\title{
CTDP-32476: A Promising Agonist Therapy for Treatment of Cocaine Addiction
}

\author{
Zheng-Xiong $\mathrm{Xi}^{*}, 1,6$, Rui Song ${ }^{2,6}, \mathrm{Xia} \mathrm{Li}^{3}$, Guan-Yi Lu², Xiao-Qing Peng ${ }^{4}$, Yi He', Guo-Hua Bi', \\ Siyuan Peter Sheng' ${ }^{\prime}$, Hong-Ju Yang', Haiying Zhang', Jin $\mathrm{Li}^{2}$, Mark Froimowitz ${ }^{5,7}$ and Eliot L Gardner' \\ 'Neuropsychopharmacology Section, Molecular Targets and Medications Discovery Branch, Intramural Research Program, National Institute on \\ Drug Abuse, Baltimore, MD, USA; ${ }^{2}$ State Key Laboratory of Toxicology and Medical Countermeasures and Beijing Key Laboratory of \\ Neuropsychopharmacology, Beijing Institute of Pharmacology and Toxicology, Beijing, China; ${ }^{3}$ Department of Psychiatry, School of Medicine, \\ University of California San Diego, La Jolla, CA, USA; ${ }^{4}$ Department of Behavioral Health, Saint Elizabeth's Hospital, Washington, DC, USA; \\ ${ }^{5}$ Massachusetts College of Pharmacy and Health Sciences, Boston, MA, USA
}

\begin{abstract}
Agonist-replacement therapies have been successfully used for treatment of opiate and nicotine addiction, but not for cocaine addiction. One of the major obstacles is the cocaine-like addictive potential of the agonists themselves. We report here an atypical dopamine (DA) transporter (DAT) inhibitor, CTDP-32476, that may have translational potential for treating cocaine addiction. In vitro ligand-binding assays suggest that CTDP-32476 is a potent and selective DAT inhibitor and a competitive inhibitor of cocaine binding to the DAT. Systemic administration of CTDP-32476 alone produced a slow-onset, long-lasting increase in extracellular nucleus accumbens DA, locomotion, and brain-stimulation reward. Drug-naive rats did not self-administer CTDP-32476. In a substitution test, cocaine self-administration rats displayed a progressive reduction in CTDP-32476 self-administration with an extinction pattern of drug-taking behavior, suggesting significantly lower addictive potential than cocaine. Pretreatment with CTDP-32476 inhibited cocaine self-administration, cocaineassociated cue-induced relapse to drug seeking, and cocaine-enhanced extracellular DA in the nucleus accumbens. These findings suggest that CTDP-32476 is a unique DAT inhibitor that not only could satisfy 'drug hunger' through its slow-onset long-lasting DAT inhibitor action, but also render subsequent administration of cocaine ineffectual-thus constituting a novel and unique compound with translational potential as an agonist therapy for treatment of cocaine addiction.
\end{abstract}

Neuropsychopharmacology (2017) 42, 682-694; doi:I0.I038/npp.2016.155; published online 21 September 2016

\section{INTRODUCTION}

Cocaine addiction is a chronic brain disease characterized by loss of control over drug intake and high rates of relapse following detoxification and abstinence (Everitt et al, 2008; Kalivas and Volkow, 2005). Although several pharmacological agents have been tested as treatments for cocaine addiction, none has proven effective (Carroll et al, 2006; Gorelick et al, 2004; Vocci and Ling, 2005; Xi and Gardner, 2008). Cocaine is a monoamine transport (MAT) blocker that inhibits the neuronal reuptake of dopamine (DA), serotonin (5-HT), and norepinephrine (Wise, 1996). Cocaine's addictive properties are believed to be mediated predominantly by blockade of presynaptic DA transport (DAT; Wise, 1996). It has therefore been proposed that a MAT or DAT inhibitor may act as a substitute for cocaine in

*Correspondence: Dr Z-X Xi, Intramural Research Program, National Institute on Drug Abuse, 250 Bayview Boulevard, Baltimore, MD 21224 , USA, Tel: + | 443740 25 17+| 443740 25 17, Fax: +| 443740 278।,

E-mail: zxi@intra.nida.nih.gov

${ }^{6}$ These authors contributed equally to this work.

${ }^{7}$ Current address: 90 Eastbourne Road, Newton, MA 02459, USA.

Received 12 February 2016; revised 19 July 2016; accepted 31 July 2016; accepted article preview online 18 August 2016 drug-dependent individuals (Gardner et al, 2006; Gorelick et al, 2004; Grabowski et al, 2004; Runyon and Carroll, 2006). A conceptually similar approach has proven effective for opiate addiction (using methadone as the substitute opiate) and for smoking cessation (using varenicline or nicotine to substitute for tobacco-derived nicotine) in a subpopulation of addicts (Gerra et al, 2009; Silagy et al, 2004). Several DAT inhibitors such as GBR-12909 and methylphenidate have been examined for treatment of cocaine addiction (Howell and Wilcox, 2001; Newman and Kulkarni, 2002; Platt et al, 2002; Rothman et al, 2008; Runyon and Carroll, 2006). However, none has proven successful because of significant abuse liability and/or significant cardiovascular side-effects as produced by GBR-12909 (Rothman et al, 2008).

Given that methadone is a relatively long-acting opioid receptor agonist and nicotine-replacement therapies have slow-release as a feature, we proposed that a MAT or DAT inhibitor with a slow-onset, long-acting profile might have potential as an agonist therapy for treating cocaine addiction (Froimowitz et al, 2000; Gardner et al, 2006; Peng et al, 2010). However, the tested compounds in those studies were nonselective MAT inhibitors, which displayed high psychomotor-stimulation and functionally enhanced cocaine's action on extracellular DA and brain-stimulation 
reward (BSR, Gardner et al, 2006; Peng et al, 2010), suggesting that MAT inhibitors with slow-onset long-lasting profiles have less than desirable therapeutic potential. Several other ligands such as GBR-12909, PTT [2 $\beta$-propanoyl-3 $\beta$-(4tolyl)-tropane], and RTI (Research Triangle Institute) compounds (3-phenyltropane analogs) have been previously thought to be 'slow-onset long-acting' DAT inhibitors (Howell and Wilcox, 2001; Rothman et al, 2008). However, in vivo microdialysis and fast-cyclic voltammetry studies suggest that they are actually fast-onset (Espana et al, 2008) and have only slightly longer durations of action than cocaine $(2-3 \mathrm{~h}$ vs $1-2 \mathrm{~h})$ with respect to enhanced extracellular nucleus accumbens (NAc) DA (Baumann et al, 1994; Budygin et al, 2000; Kimmel et al, 2008; Kimmel et al, 2007; Nakachi et al, 1995). These data suggest that such DAT inhibitors may have similar addictive potential as cocaine. Therefore, a truly slow-onset long-acting DAT inhibitor as an agonist therapy for treating cocaine addiction has not yet been well studied.

In addition, we have recently reported that methadone is more than simply 'slow heroin' (Peng et al, 2010). It not only displays a long-lasting opiate agonist profile, but also renders subsequent administration of heroin ineffectual (Allouche et al, 2014). As a consequence, we have proposed that a successful agonist therapy for cocaine addiction must have two basic properties, to wit: (1) a slow-onset long-lasting DAT inhibitor profile, to satisfy drug hunger, and (2) the ability to block subsequent cocaine action (Peng et al, 2010).

Here, we report on a piperidine compound-CTDP-32476 (named by the NIDA Cocaine Treatment Development Program), one of very few DAT inhibitors with slow-onset long-duration profiles (Froimowitz et al, 2007). Unlike our previously studied compounds CTDP-30640 and CTDP-31345 (each of which is a prodrug), CTDP-32476 is a metabolically stable DAT inhibitor. It has potent affinity for the DAT, moderate affinity for the NET, and little affinity for the SERT with similar results on uptake assays at the three transporter systems (Froimowitz et al, 2007). In the present study, we evaluated the potential utility of this compound for treatment of cocaine addiction in a wide variety of preclinical models. We first compared the binding properties of cocaine, methylphenidate, and CTDP-32476 on the DAT and the possible interactions of CTDP-32476 with cocaine at the DAT ex vivo. We then evaluated the potential abuse potential of CTDP-32476 by itself and its pharmacological interactions with cocaine in multiple animal models of cocaine addiction.

\section{MATERIALS AND METHODS}

\section{Animals}

Male Long-Evans rats (Charles River Laboratories, Raleigh, NC) initially weighing 250-300 g were used for all experiments. They were housed individually in a climate-controlled animal colony room on a reverse light-dark cycle (lights on at 1900 hours, lights off at 0700 hours) with free access to food and water. The animals were maintained in a facility fully accredited by the Association for Assessment and Accreditation of Laboratory Animal Care International. All experimental procedures were performed in accordance with the 'Guide for the Care and Use of Laboratory Animals'
(National Research Council, 2011) and were approved by the Animal Care and Use Committee of the National Institute on Drug Abuse of the U.S. National Institutes of Health.

\section{Experiment 1: In vitro Ligand-Binding Assays}

Transporter-binding assays. The protocols for cell membrane preparations were slightly modified from a previous report (Reavill et al, 2000). The membranes were prepared from human embryonic kidney 293 cells (HEK293 cells) stably expressing human DATs. The affinities of the test compounds (CTDP-32476, methylphenidate, cocaine) for DAT were determined by competitive interaction with $\left[{ }^{3} \mathrm{H}\right]$ WIN-35428, respectively, as previously described (Jin et al, 2012). Briefly, stored membranes were suspended in reaction buffer. Competitive binding assays were performed in reaction buffer containing $50 \mu \mathrm{g}$ membrane protein, $\left[{ }^{3} \mathrm{H}\right]$ WIN-35428 (10 nM) and various concentrations of CTDP-32476 $\left(10^{-8}\right.$ to $\left.10^{-4} \mathrm{M}\right)$, methylphenidate $\left(10^{-8}\right.$ to $\left.10^{-4} \mathrm{M}\right)$ or cocaine $\left(10^{-8}\right.$ to $\left.10^{-4} \mathrm{M}\right)$ at $21^{\circ} \mathrm{C}$ for $60 \mathrm{~min}$. Non-specific binding to DAT was determined with $10 \mu \mathrm{M}$ nomifensine. The reaction was terminated by filtration through Whatman GF/C filters presoaked in $0.3 \%$ polyethyleneimine for $30 \mathrm{~min}$. The filter was then washed three times with $3 \mathrm{ml}$ of cold $50 \mathrm{mM}$ Tris- $\mathrm{HCl}$.

$\left[{ }^{3} \mathrm{H}\right]$-cocaine-binding assays. The effects of CTDP-32476 or methylphenidate on $\left[{ }^{3} \mathrm{H}\right]$-cocaine binding to cell membranes for DAT were determined in the presence of $50 \mathrm{nM}$ $\left[{ }^{3} \mathrm{H}\right]$-cocaine and varying concentrations of CTDP-32476 $\left(10^{-12}\right.$ to $\left.10^{-4} \mathrm{M}\right)$ or methylphenidate $\left(10^{-9}\right.$ to $\left.10^{-4} \mathrm{M}\right)$. After $60 \mathrm{~min}$ incubation at $21^{\circ} \mathrm{C}$, the reaction was terminated by filtration through Whatman GF/C filters presoaked in $0.3 \%$ polyethyleneimine for $30 \mathrm{~min}$. Although $\left[{ }^{3} \mathrm{H}\right]-$ cocaine binding has a high-dissociation rate (Reith et al, 1998), a fast single-manifold vacuum filtration system was used. The filter was then washed three times with $3 \mathrm{ml}$ $50 \mathrm{mM}$ Tris-HCl. Non-specific binding was determined in the presence of $50 \mathrm{nM}\left[{ }^{3} \mathrm{H}\right]$-cocaine and $20 \mu \mathrm{M}$ nomifensine. Specific transporter binding was calculated by subtracting non-specific binding from total ligand binding. $\mathrm{IC}_{50}$ values of the test compounds were determined using a method previously described (Cheng and Prusoff, 1973). $K_{i}$ value was calculated using the equation $\mathrm{K}_{\mathrm{i}}=\mathrm{IC}_{50} /(1+[\mathrm{S}] / \mathrm{Kd})$ ([S]- radioligand substrate concentration). All data are presented as mean values of 2-3 independent assays.

\section{Experiment 2: Locomotor Activity}

This experiment was designed to compare the psychomotor stimulating effects of cocaine with those of CTDP-32476. Drug-naive rats were placed in locomotor detection chambers (Accuscan, Columbus, $\mathrm{OH}$ ) and habituated for $1 \mathrm{~h}$. Rats were then divided into 4 groups. Each group randomly received vehicle ( $1 \mathrm{ml} / \mathrm{kg} 25 \% 2$-hydroxypropyl- $\beta$-cyclodextrin) or one dose of cocaine $(10 \mathrm{mg} / \mathrm{kg}$, i.p.) or one of two doses of CTDP-32476 (3, $10 \mathrm{mg} / \mathrm{kg}$, i.p.). Following the injection, locomotor activity was recorded for $6 \mathrm{~h}$ in $10 \mathrm{~min}$ bins, and distance counts were used to evaluate the effects of cocaine or CTDP-32476 on locomotion. 


\section{Experiment 3: Intracranial Electrical BSR}

Surgery and general procedures for electrical BSR were as we have reported previously (Xi et al, 2008). Briefly, the surgery was performed under sodium pentobarbital anesthesia (65 mg/kg i.p.). A unilateral monopolar stainless-steel stimulating electrode was placed into the medial forebrain bundle at the anterior-posterior level of the lateral hypothalamus (AP $-2.56, \mathrm{ML} \pm 1.9$, and $\mathrm{DV}-8.6$ ). After 7 days of recovery from surgery, rats were allowed to self-train (autoshape) to lever press for rewarding BSR. Once stable BSR behavior was achieved ( $<10 \%$ variation in $\theta_{0}$ over 5 continuous days), animals received an intraperitoneal (i.p.) injection of cocaine $(10 \mathrm{mg} / \mathrm{kg})$ or one of two doses of CTDP-32476 (3, $10 \mathrm{mg} / \mathrm{kg})$. At $30 \mathrm{~min}$ after injection, the BSR test began. The BSR threshold $\left(\theta_{0}\right)$ was defined as the minimum frequency at which the animal responded for rewarding stimulation, which was mathematically calculated using 'best-fit' mathematical algorithms (Xi et al, 2008). After each test, animals received an additional 5-7 days of BSR re-stabilization until a new baseline $\theta_{0}$ was established. The order of testing for different drug doses was counterbalanced.

\section{Experiment 4: Intravenous Self-Administration}

Cocaine self-administration under fixed-ratio reinforcement. The methods for catheter surgery and selfadministration training were as previously reported (Xi et al, 2008). After 5-7 days of recovery from surgery, each rat was placed into a test chamber (Med Associates, Saint Albans, VT) and allowed to lever press for i.v. saline $(0.08 \mathrm{ml} /$ infusion $)$, cocaine $(0.5 \mathrm{mg} / \mathrm{kg} /$ infusion $)$, or CTDP-32476 $(0.5,1.0 \mathrm{mg} / \mathrm{kg} /$ infusion) infusion under fixed-ratio 1 (FR1) reinforcement. Each session lasted $3 \mathrm{~h}$. The FR1 reinforcement schedule was used for 5 days, and then switched to FR2 for an additional 10 days. Lever responding and drug infusions for cocaine and CTDP-32476 were compared. In order to avoid cocaine overdose, animals were limited to 50 cocaine infusions per session. The effects of CTDP-32476 (3, 10, $20 \mathrm{mg} / \mathrm{kg}$, i.p.) on cocaine self-administration were assessed.

CTDP-32476 substitution for cocaine self-administration under FR2 reinforcement. In this experiment, animals were initially trained to self-administer cocaine and then cocaine was replaced by the same dose of CTDP-32476 $(0.5 \mathrm{mg} / \mathrm{kg} /$ infusion $)$ or saline $(0.1 \mathrm{ml} /$ infusion $)$ for 7 consecutive days to determine if CTDP-32476 can maintain stable self-administration.

Cocaine self-administration under progressive-ratio reinforcement. The methods for cocaine self-administration under PR reinforcement were identical to those reported previously (Xi et al, 2008). After establishing a stable baseline under FR2 reinforcement, the subjects were divided into three subgroups for three different doses $(0.25,0.5,1.0 \mathrm{mg} /$ $\mathrm{kg} /$ infusion) of cocaine or dose-matched CTDP-32476 selfadministration under PR reinforcement. During PR conditions, the work requirement (lever presses) needed to receive a single i.v. drug infusion was progressively raised within each test session according to the following PR series: 1, 2, 4, $6,9,12,15,20,25,32,40,50,62,77,95,118,145,178,219$,
$268,328,402,492$, and 603 until the break point was reached (Richardson and Roberts, 1996). The break point was defined as the maximal work load (ie, number of lever presses) completed for the last cocaine infusion prior to a 1-h period during which no infusions were obtained by the animal. Animals were allowed to continue daily sessions of cocaine self-administration under PR reinforcement until day-to-day variability in the break point fell within 1-2 ratio increments for 3 consecutive days. Then, cocaine was replaced by the same doses of CTDP-32476 $(0.25,0.5,1.0 \mathrm{mg} / \mathrm{kg} /$ infusion $)$ for 3 consecutive days. The break points under each dose of cocaine or CTDP-32476 were compared.

In four additional groups of rats, the effects of CTDP-32476 pretreatment (vehicle, $3,10,20 \mathrm{mg} / \mathrm{kg}$, i.p., $30 \mathrm{~min}$ prior to the test session) on PR cocaine self-administration were evaluated.

Multiple-dose cocaine self-administration. To further determine whether CTDP-32476 altered cocaine's rewarding efficacy, we also investigated the effects of CTDP-32476 pretreatment on cocaine self-administration maintained by a full range of cocaine doses $(0.03125,0.0625,0.125,0.25,0.5$, and $1.0 \mathrm{mg} / \mathrm{kg} /$ infusion) in a single session. The session consisted of six sequential 20-min components, each preceded by a 10 -min time-out period for changing the cocaine dose. The infusion volumes and durations in each component were identical except that cocaine concentrations for corresponding unit cocaine doses differed. There was a 30 -min extinction period $(0 \mathrm{mg} / \mathrm{kg}$ cocaine) before daily cocaine self-administration acquisition. After stable cocainemaintained responding was achieved (ie, a minimum of $10 \mathrm{mg} / \mathrm{kg}$ cocaine intake within a session; $<10 \%$ variation in total number of cocaine infusions for 3 consecutive days), each rat randomly received either vehicle or 1 of 2 doses of CTDP-32476 (10, $20 \mathrm{mg} / \mathrm{kg}$, i.p.) $30 \mathrm{~min}$ prior to the multiple-dose cocaine self-administration test session. Animals then received an additional 5-7 days of cocaine selfadministration until the baseline response rate was reestablished prior to testing the next dose of CTDP-32476. The order of testing for the various doses of drug or vehicle was counterbalanced.

\section{Experiment 5: Cocaine- or Cue-Primed Reinstatement of Drug-Seeking Behavior}

Effects of CTDP-32476 on cocaine-primed reinstatement. After stable cocaine self-administration was achieved for at least 3-5 days, the animals underwent extinction training, during which cocaine was replaced by saline, and the light and sound cues that previously accompanied cocaine infusions were turned off. After drug-seeking behavior was extinguished, defined as $\leq 10$ active lever presses during each 3 -h session for at least 3 consecutive days, the animals were divided into 3 dose groups to evaluate the effects of CTDP-32476 (0, 10, or $20 \mathrm{mg} / \mathrm{kg}$, i.p.) on cocaine-primed reinstatement of drug-seeking behavior ( $n=7-8$ per group).

Effects of chronic CTDP-32476 on cue-induced reinstatement. After meeting the above self-administration criteria, additional groups of rats underwent extinction as described above in the presence or absence of CTDP-32476 pretreatment (vehicle, $10,20 \mathrm{mg} / \mathrm{kg}$, i.p., $30 \mathrm{~min}$ prior to extinction 
testing for 7 days). At $24 \mathrm{~h}$ after the last extinction session, cue-primed reinstatement testing began. During the testing, 1-2 non-contingent presentations of the cocaine-associated light and tone were given at the onset of the test session because toward the end of extinction training, most rats did not approach the lever. Subsequent lever presses then led to response-contingent deliveries of the same conditioned lighttone cues. On the test day, there was no CTDP-32476 administration in the three groups of rats. Then, an additional cocaine-primed reinstatement test followed $24 \mathrm{~h}$ after the cueprimed reinstatement test in the same groups of rats.

\section{Experiment 6: In vivo Brain Microdialysis}

The intracranial guide cannula surgery and in vivo brain microdialysis procedures were identical to those previously reported (Li et al, 2010). In brief, rats were anesthetized with sodium pentobarbital (50 mg/kg i.p.) and brain microdialysis guide cannulae were surgically implanted into the NAc (AP +1.6, ML 2.0, DV - 4.0).

In vivo microdialysis experiments were begun after 5-7 days of recovery from surgery. Microdialysis probes were inserted into the NAc through the previously implanted guide cannulae at least $12 \mathrm{~h}$ before onset of experimentation to minimize damage-induced neurochemical release during the experiment. After $1 \mathrm{~h}$ of baseline sample collection, vehicle, cocaine (10 mg/kg, i.p.), or CTDP-32476 (10, $20 \mathrm{mg} /$ $\mathrm{kg}$, i.p.) was administered systemically to determine time course of action of the drugs on extracellular NAc DA.

To compare the relative potency of action of cocaine and CTDP-32476 on NAc DA, escalating concentrations of cocaine or CTDP-32476 $(1,10,100,1000 \mu \mathrm{M})$ were locally infused into the NAc. We also investigated and compared the effects of intra-NAc CTDP-32476 $(30 \mu \mathrm{M})$ pretreatment and co-administration with cocaine on cocaine-enhanced extracellular NAc DA. After collection, all samples were frozen at $-80^{\circ} \mathrm{C}$ until analyzed. Microdialysate DA was measured using high-performance liquid chromatography coupled with electrochemical detection.

\section{Drugs and Chemicals}

Cocaine (NIDA, Baltimore, MD) was dissolved in sterile physiological saline. CTDP-32476 [(RR/SS)-2-[1-(4-chlorophenyl)-3-methylbutyl]piperidinium chloride] was synthesized at the Massachusetts College of Pharmacy and Health Sciences using synthesis procedures previously described (Froimowitz et al, 2007). It was dissolved in $25 \%$ or $5 \%$ 2-hydroxypropyl- $\beta$-cyclodextrin for i.p. or i.v. administration, respectively.

\section{Data Analyses}

All data are presented as means \pm SEM. One-way or two-way analyses of variance (ANOVA) were used to analyze the effects of cocaine and/or CTDP-32476 on locomotion, selfadministration, or NAc DA (see the 'Results' section for details). Individual group comparisons were carried out using the Student-Newman-Keuls method.

\section{RESULTS}

\section{CTDP-32476 is a Highly Potent Human DAT Inhibitor}

Figure 1a shows the structures of cocaine, methylphenidate, and CTDP-32476. Figure $1 \mathrm{~b}$ shows the binding properties of cocaine, methylphenidate, and CTDP-32476 on the DAT using HEK293 cells transfected with the human DATdemonstrating that all three ligands significantly inhibited<smiles>COC(=O)C1C(OC(=O)c2ccccc2)CC2CCC1N2C</smiles>

Cocaine

b

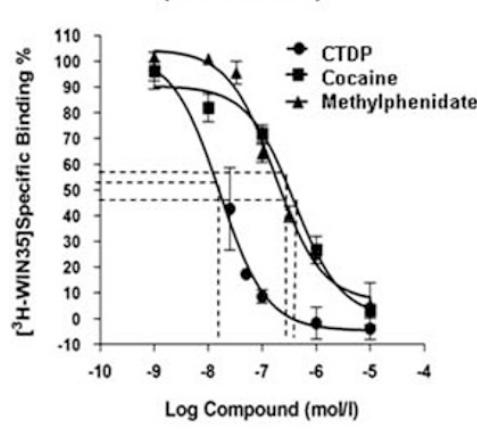<smiles>COC(=O)C(c1ccccc1)C1CCCCN1</smiles>

Methylphenidate

(HEK293-DAT)

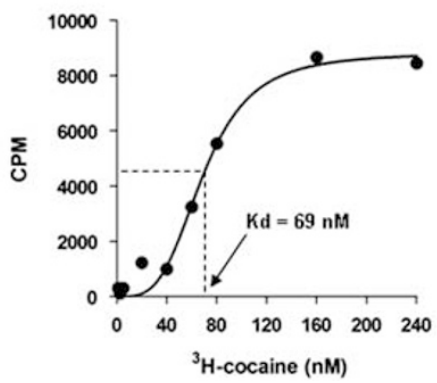

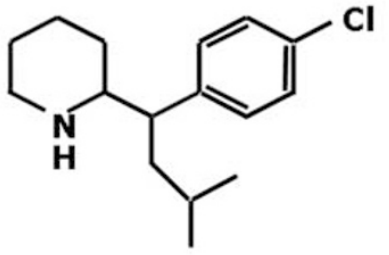

CTDP 32,476

d

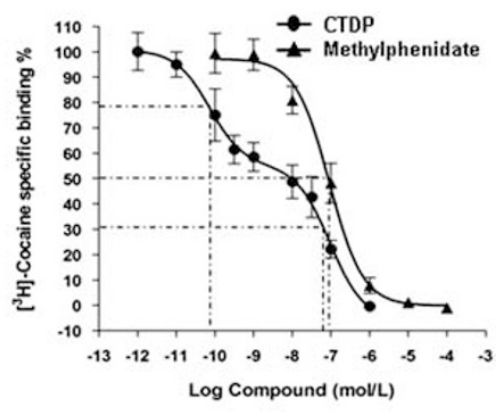

Figure I Ligand-binding properties at the DAT expressed on HEK293 cells. (a) Chemical structures of the three test ligands-cocaine, methylphenidate, and CTDP-32476. (b) The three test ligands inhibited $\left[{ }^{3} \mathrm{H}\right]-\mathrm{WIN}-35428$ binding to human DAT expressed in HEK293 cells in a concentration-dependent manner. CTDP-32476 displayed $\sim 20$-fold higher binding affinity $\left(K_{i}=12 \mathrm{nM}\right)$ for DAT than cocaine ( $\left.279 \mathrm{nM}\right)$ or methylphenidate (I07 nM). (c) Concentration-dependent binding curve of $\left[{ }^{3} \mathrm{H}\right]$-cocaine for DAT; (d) CTDP-32476 and methylphenidate inhibited [ $\left.{ }^{3} \mathrm{H}\right]$-cocaine binding at the DAT in a concentration-manner, with CTDP-32476 displaying higher affinity for DAT than methylphenidate and showing two binding sites on the DAT. 
$\left[{ }^{3} \mathrm{H}\right]$ WIN-35428 binding to DAT in a concentrationdependent manner. The $\mathrm{K}_{\mathrm{i}}$ values of these 3 compounds are $12 \pm 3 \mathrm{nM}$ (CTDP-32476), $107 \pm 48 \mathrm{nM}$ (methylphenidate), and $279 \pm 65 \mathrm{nM}$ (cocaine), suggesting that CTDP-32476 is a highly potent DAT inhibitor with $\sim 20$ fold higher affinity for the DAT than cocaine.

\section{CTDP-32476 is a Competitive Cocaine-binding Inhibitor at the DAT}

We then investigated the potential interactions of CTDP-32476 and cocaine binding at the DAT. Figure 1c shows $\left[{ }^{3} \mathrm{H}\right]$-cocaine binding at the DAT, with a $\mathrm{K}_{\mathrm{d}}$ value of $69 \mathrm{nM}$. Figure 1d shows $\left[{ }^{3} \mathrm{H}\right]$-cocaine $(50 \mathrm{nM})$ binding curves at the DAT in the absence or presence of different concentrations of CTDP-32476 or methylphenidate, illustrating that: (1) both compounds significantly inhibit $\left[{ }^{3} \mathrm{H}\right]-$ cocaine binding at the DAT in a concentration-dependent manner; (2) CTDP-32476 is more potent than methylphenidate in blocking $\left[{ }^{3} \mathrm{H}\right]$-cocaine binding; and (3) CTDP-32476 has two binding sites on the DAT-a highaffinity binding site with a $K_{\text {-High }}$ value of $0.12 \pm 0.08 \mathrm{nM}$ and a low-affinity binding site with a $\bar{K}_{\text {i-Low }}$ of $123 \pm 35.8 \mathrm{nM}$. Methylphenidate displayed only one medium affinity binding site with a $\mathrm{K}_{\mathrm{i}}$ value of $58.5 \pm 23.5 \mathrm{nM}$. These findings suggest that CTDP-32476 is a potent cocainebinding inhibitor at the DAT.

\section{CTDP-32476 is a Long-Acting DAT Inhibitor After Systemic Administration}

Figure 2 shows that acute cocaine $(10 \mathrm{mg} / \mathrm{kg}$, i.p.) produced a fast-onset (within $10 \mathrm{~min}$ ) and short-duration $(\sim 1 \mathrm{~h})$ increase in locomotion (Figures 2a and b), electrical BSR (Figure 2d), and extracellular NAc DA (Figure 2e). In contrast, systemic administration of CTDP-32476 (3, 10, $20 \mathrm{mg} / \mathrm{kg}$, i.p.) produced a slow-onset (20-60 min), long-duration (6-12 h) increase in these three parameters in a dose-dependent manner (Figures 2a, c, d, and e). A two-way ANOVA for repeated measures over time revealed a statistically significant treatment (cocaine vs CTDP-32476 or CTDP-32476 vs methylphenidate/GBR-12909) main effect (Figure 2a: $F_{3,28}=16.36, \quad p<0.001$; Figure 2b: $F_{3,27}=12.16, p<0.01$; Figure 2c: $F_{2,21}=10.34, p<0.01$; Figure $2 \mathrm{~d}: F_{3,27}=9.34$, $p<0.01$; and Figure 2e: $\left.F_{3,27}=10.61, p<0.001\right)$ and time main effect (Figure 2a: $F_{38,1064}=18.89, p<0.001$; Figure $2 \mathrm{~b}$ : $F_{38,364}=18.89, p<0.001$; Figure $2 \mathrm{c}: F_{38,798}=18.89, p<0.001$; Figure 2d: $F_{10}, 270=9.21, p<0.01$; and Figure 2e: $F_{20}$, $360=23.65, p<0.001)$. To determine whether this slowonset long-lasting profile is unique to CTDP-32476, we compared the pharmacological action of CTDP-32476 with two other well-characterized DAT inhibitors-methylphenidate and GBR-12909. Figure 2c shows that CTDP-32476 is significantly different from both compounds. Systemic administration of methylphenidate or GBR-12909 actually produced fast-onset (very similar to cocaine) and relatively long-duration $(2 \mathrm{~h} v s 1 \mathrm{~h}$ ) increased locomotion (Figure $2 \mathrm{~b}$ ), whereas CTDP-32476 produced pronounced slow-onset (20$60 \mathrm{~min} v s<10 \mathrm{~min}$ ) and long-duration (at least $6 \mathrm{~h} v s \mathrm{1}-2 \mathrm{~h}$ ) increased locomotion when compared with cocaine (Figure 2a) or methylphenidate/GBR-12909 (Figure 2c) at the same doses. In contrast to the above findings, local administration of CTDP-32476 into the NAc produced a cocaine-like fast-onset increase in extracellular DA in a concentration-dependent manner (Figure 2f, $\mathrm{F}_{1,13}=0.34$, $p>0.05)$, suggesting that the slow-onset long-lasting action produced by systemic (i.p.) administration of CTDP-32476 is due to its peripheral pharmacokinetic profile.

\section{CTDP-32476 Displays Low Addictive Potential in Animal Models}

We then examined whether this unique slow-onset longacting DAT inhibitor CTDP-32476 displays less addictive potential than cocaine in animal models. Figure 3 a shows the time courses of acquisition of intravenous cocaine $(0.5 \mathrm{mg} / \mathrm{kg}$ per infusion), CTDP-32476 (0.5, $1.0 \mathrm{mg} / \mathrm{kg}$ per infusion), or saline $(0.1 \mathrm{ml} /$ infusion $)$ self-administration in four groups of drug-naive rats under FR2 reinforcement, demonstrating that drug-naive rats rapidly and reliably acquired stable selfadministration of cocaine, but not of saline or CTDP-32476. A two-way ANOVA for repeated measures over time (sessions) revealed a statistically significant treatment main effect $\left(F_{3,25}=31.54, p<0.001\right)$. Individual group comparisons revealed a statistically significant difference in selfadministration between the cocaine and saline groups $(p<0.001)$, and between the cocaine and CTDP-32476 groups $(p<0.001)$, but not between the saline and CTDP-32476 groups ( $p=N S$ ). These findings suggest that CTDP-32476 does not have cocaine-like appetitive properties in drug-naive rats.

To further explore the abuse liability of this compound (a critical obstacle in development of agonist therapy for cocaine addiction), we carried out drug substitution tests to determine whether CTDP-32476 could maintain a cocainelike pattern of self-administration in rats trained to selfadminister cocaine. Figure $3 \mathrm{~b}$ shows the results of CTDP-32476 substitution for cocaine under FR2 reinforcement, illustrating that the same unit dose $(0.5 \mathrm{mg} / \mathrm{kg}$ per infusion) of CTDP-32476 did not sustain stable selfadministration, but displayed a progressive reduction in drug intake over time (8 sessions) with a typical extinction pattern of self-administration within each substitution session. Saline failed to maintain self-administration, producing rapid extinction of drug-seeking behavior. A twoway repeated measures ANOVA revealed a statistically significant treatment (saline vs CTDP-32476) main effect $\left(F_{2,18}=32.85, p<0.001\right)$ and time main effect $\left(F_{10,140}=53.49\right.$, $p<0.001)$.

The self-administration break point under progressiveratio (PR) reinforcement (ie, maximal work load an animal is willing to expend to receive a drug infusion) is often used to evaluate a drug's rewarding efficacy (Richardson and Roberts, 1996; Xi et al, 2008). A higher break point for drug self-administration is generally believed to indicate higher addictive potential. Figure $3 \mathrm{c}$ shows mean PR break points for three different doses of cocaine or CTDP-32476 $(0.25,0.5$, and $1.0 \mathrm{mg} / \mathrm{kg} /$ infusion), illustrating that cocaine produced a dose-dependent increase in PR self-administration break point. However, when cocaine was replaced by CTDP-32476 at each dose, PR break points were significantly lower than those seen with cocaine PR self-administration. In addition, substitution of CTDP-32476 for cocaine also caused a progressive reduction in drug-taking behavior over time ( 3 
a

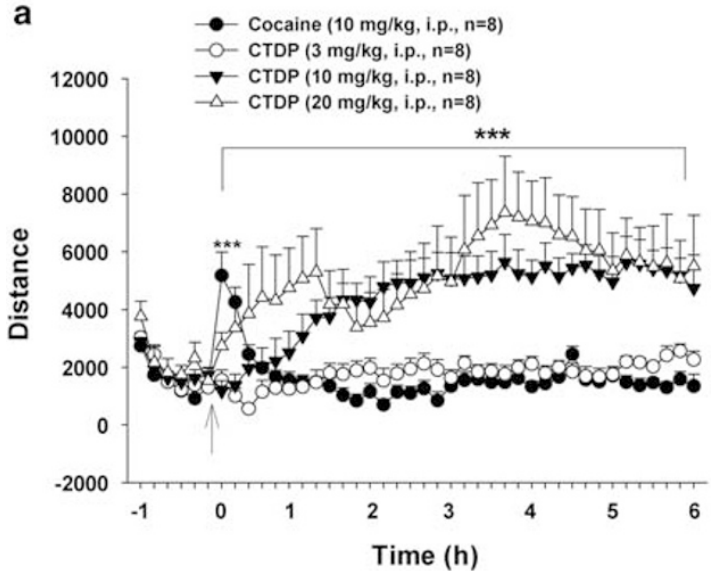

C

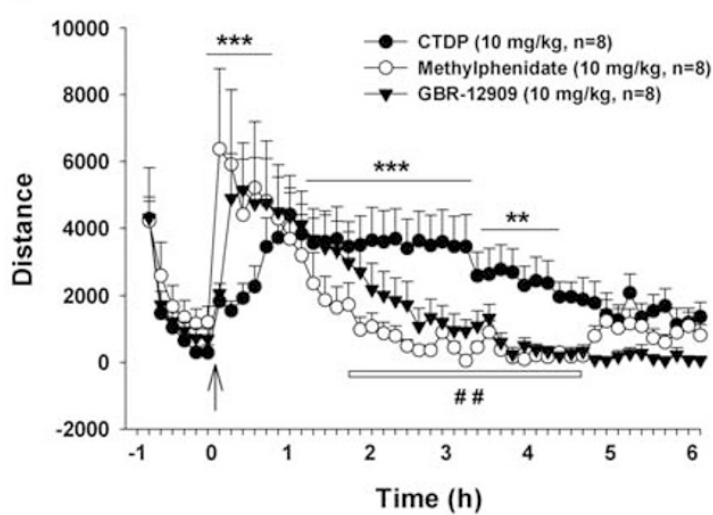

e

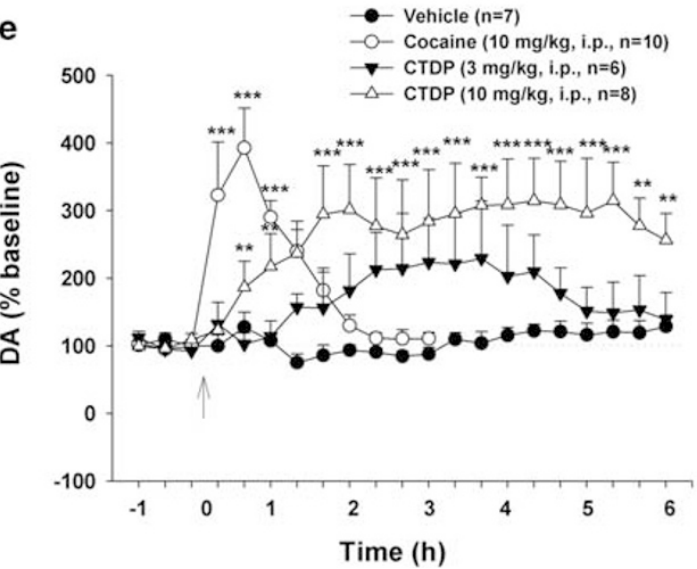

b
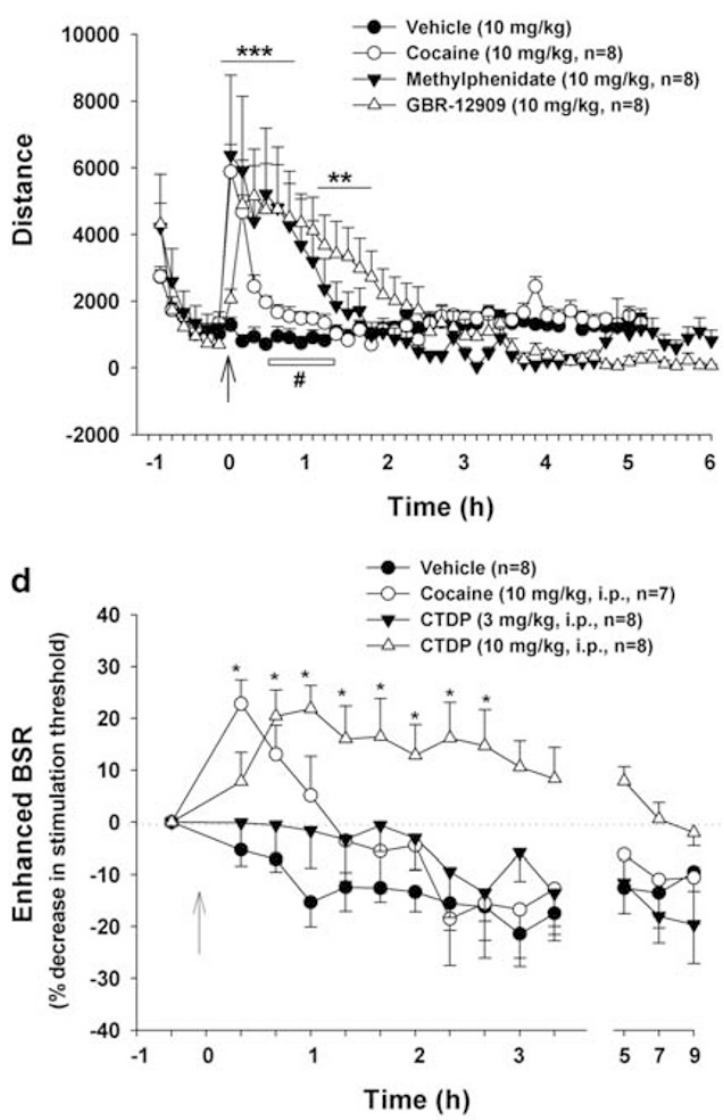

f

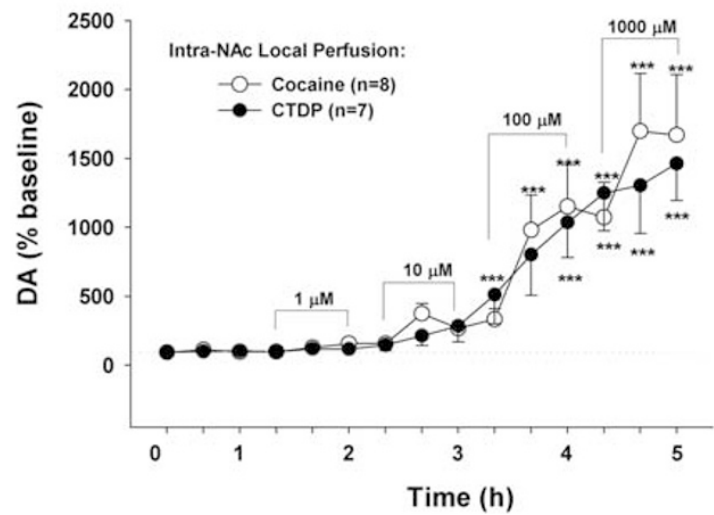

Figure 2 The slow-onset long-lasting profiles of CTDP-32476 after systemic administration. (a) Systemic administration of CTDP-32476 (3, 10 , and 20 mg/ kg, i.p.) produced a slow-onset long-lasting increase in locomotion compared with cocaine. (b) Systemic administration of methylphenidate or GBR-I2909 ( $10 \mathrm{mg} / \mathrm{kg}$, i.p.) produced similarly fast-onset and relatively longer-duration ( $2 \mathrm{~h} \mathrm{vs} \mathrm{I} \mathrm{h)} \mathrm{enhanced} \mathrm{locomotion} \mathrm{than} \mathrm{cocaine.} \mathrm{(c)} \mathrm{In} \mathrm{contrast} \mathrm{to} \mathrm{methylphenidate}$ or GBR-12909, systemic administration of CTDP-32476 produced significantly slower-onset, longer-duration enhanced locomotion. (d and e) Systemic administration of CTDP-32476 produced a significantly slower-onset and longer-lasting increase of electrical brain-stimulation reward (d) and extracellular NAc DA (e), compared with cocaine. (f) However, intracranial local perfusion of CTDP-32476 produced similar enhancement of extracellular NAc DA as cocaine. ${ }^{*} p<0.05$, ${ }^{*} p<0.01$, **** $p<0.00$ I, compared with baseline before drug administration. ${ }^{*} p<0.05$ between cocaine and GBR-I 2909 groups in Fig. $2 \mathrm{~b} ;{ }^{\# \#} p<0.01$, between CTDP-32476 and methylphenidate groups in Figure 2c.

sessions) at each tested dose. A one-way repeated-measures ANOVA revealed a significant treatment (cocaine vs CTDP$32476)$ main effect at $0.5 \mathrm{mg} / \mathrm{kg}$ per infusion $\left(F_{5,30}=5.08\right.$, $p<0.01)$ or $1.0 \mathrm{mg} / \mathrm{kg}$ per infusion $\left(F_{5,30}=10.22, p<0.001\right)$, but not at $0.25 \mathrm{mg} / \mathrm{kg}$ per infusion $\left(F_{5,30}=2.20, p=\mathrm{NS}\right)$.
Individual group comparisons reveal a significant reduction in break point for drug self-administration when cocaine was replaced by CTDP-32476. These findings observed in three different self-administration experiments support a conclusion that CTDP-32476 is less rewarding than cocaine. 
(Naive rats, FR2)
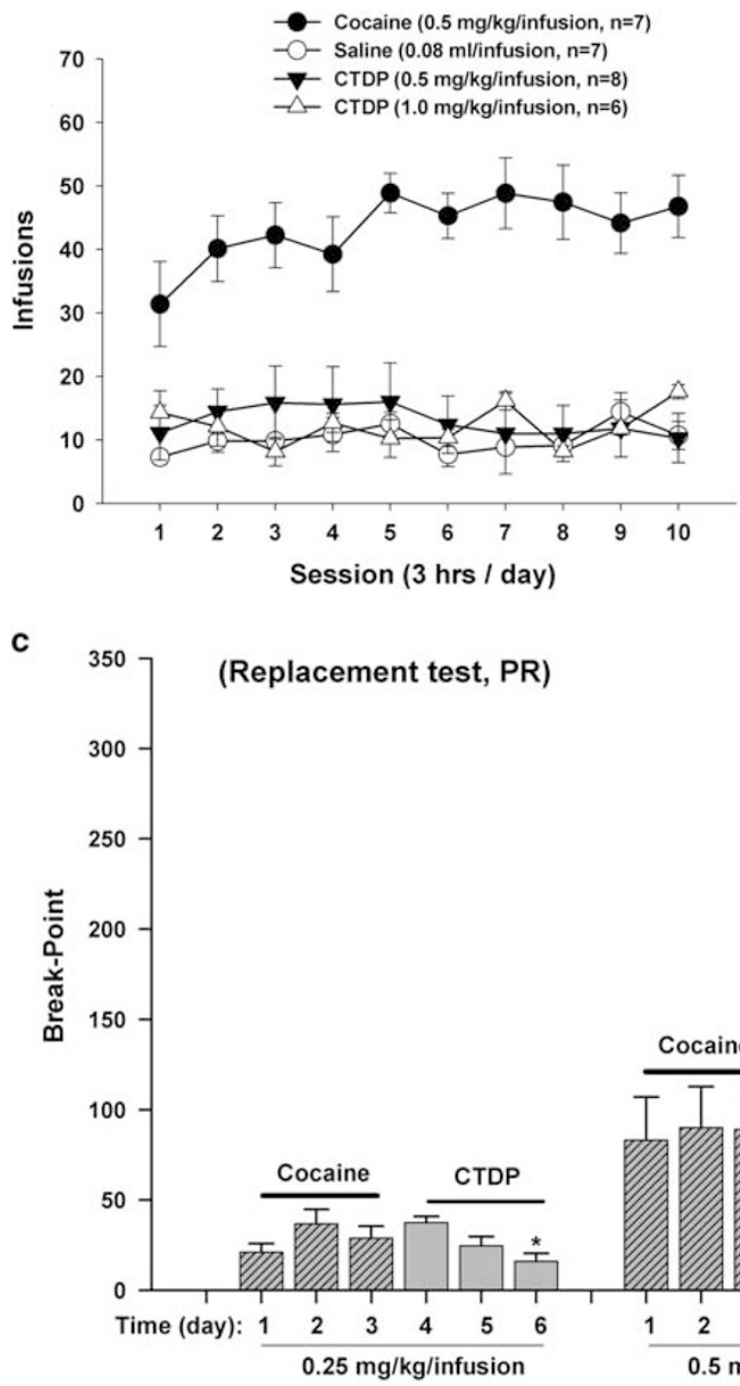

b

(Replacement test, FR2)

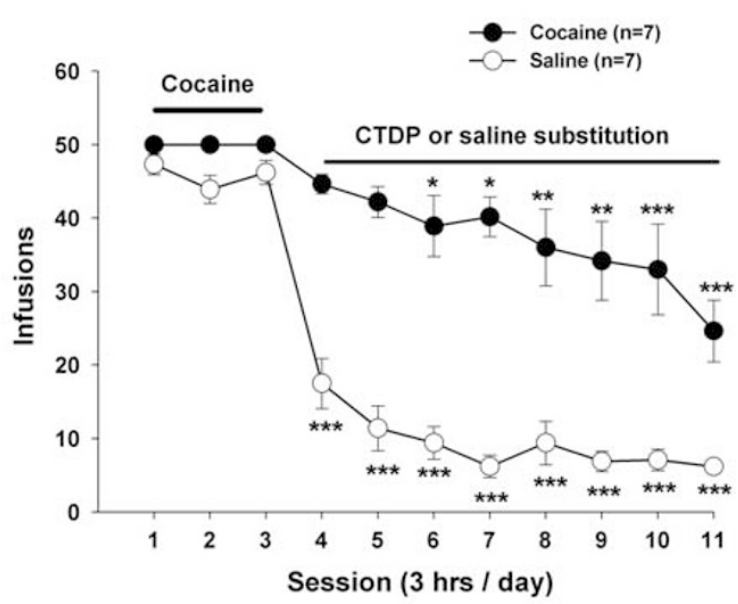

Figure 3 Evaluation of CTDP-32476's addictive potential. (a) Mean numbers of intravenous cocaine, CTDP-32476, or saline infusions during an initial 10 days of self-administration in naive rats, illustrating that naive rats rapidly learn to self-administer cocaine, but not CTDP-32476 or saline. (b) CTDP-32476 or saline substitution tests in rats previously self-administering cocaine $(0.5 \mathrm{mg} / \mathrm{kg}$ per infusion), illustrating that CTDP-32476 (0.5 mg/kg per infusion) substitution did not sustain stable self-administration; rather, CTDP-32476 self-administration displayed a progressive reduction over time (sessions) in animals previously self-administering cocaine. (c) CTDP-32476 substitution for cocaine in self-administration under progressive-ratio (PR) reinforcement, illustrating that PR break points for CTDP-32476 were significantly lower than those for equivalent doses of cocaine in rats previously self-administering cocaine. * $p<0.05, * * * 0.01$, **** $p<0.001$, compared with last day of cocaine self-administration at each dose.

\section{CTDP-32476 Pretreatment Attenuates Cocaine Self-Administration}

We then assessed whether CTDP-32476 pretreatment attenuates cocaine self-administration. Figure 4 a shows mean cocaine infusions before and after different doses of CTDP-32476 pretreatment. Pretreatment with CTDP-32476 (3, 10 , and $20 \mathrm{mg} / \mathrm{kg}$, i.p.) dose-dependently inhibited cocaine self-administration under FR2 reinforcement $\left(F_{3,31}=6.23, p<0.01\right)$, but had no effect on inactive lever responding. Figure $4 \mathrm{~b}$ shows that systemic administration of CTDP-32476 (3, 10, and $20 \mathrm{mg} / \mathrm{kg}$, i.p.) also significantly lowered the PR break point for cocaine self-administration in a dose-dependent manner $\left(F_{3,27}=3.34, p<0.05\right)$, suggesting a reduction in cocaine's rewarding effects. Individual group comparisons indicated a significant reduction in break point after $20 \mathrm{mg} / \mathrm{kg}(p<0.05)$, but not after $3 \mathrm{mg} / \mathrm{kg}$ or $10 \mathrm{mg} / \mathrm{kg}$ CTDP-32476, when compared with the vehicle control group.

To further query whether CTDP-32476 pretreatment attenuates cocaine reward in self-administration, we observed cocaine dose-response self-administration curves maintained by a range of cocaine doses $(0.03125,0.0625$, $0.125,0.25,0.5$, and $1.0 \mathrm{mg} / \mathrm{kg} /$ infusion) in the presence or absence of CTDP-32476 pretreatment. Figure 4c shows that CTDP-32476 pretreatment dose-dependently shifted the 
a

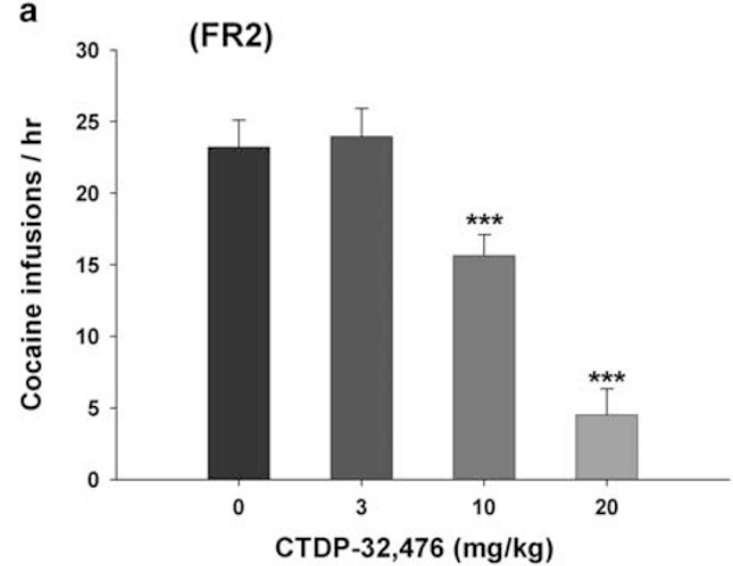

c

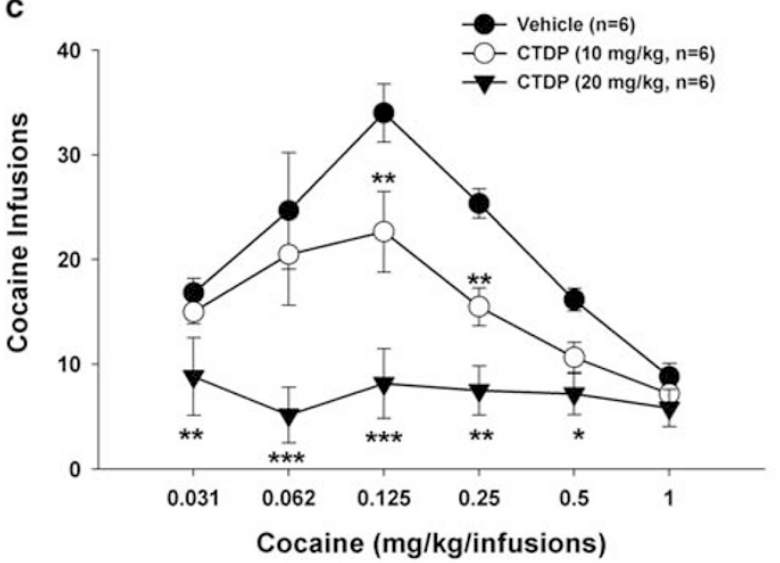

e

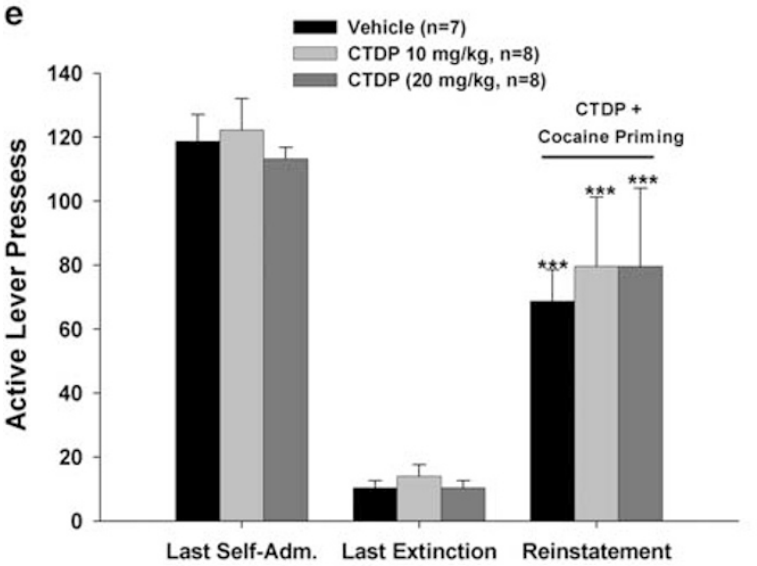

b
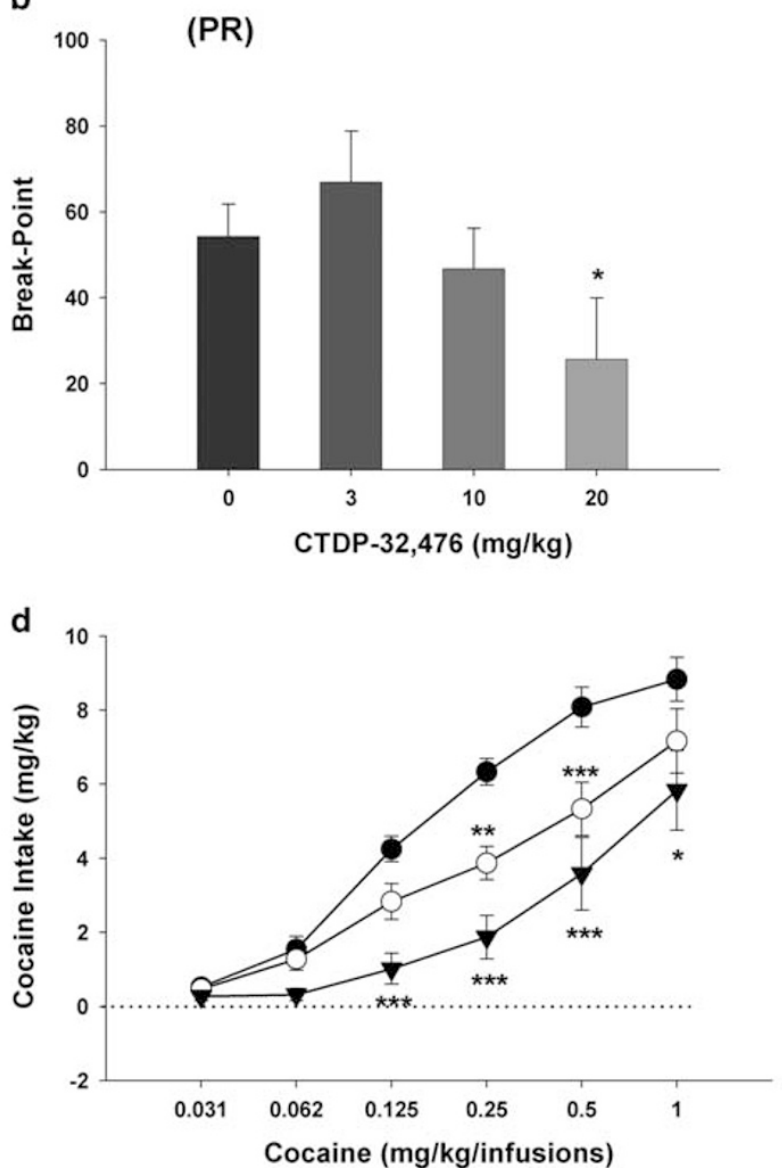

f

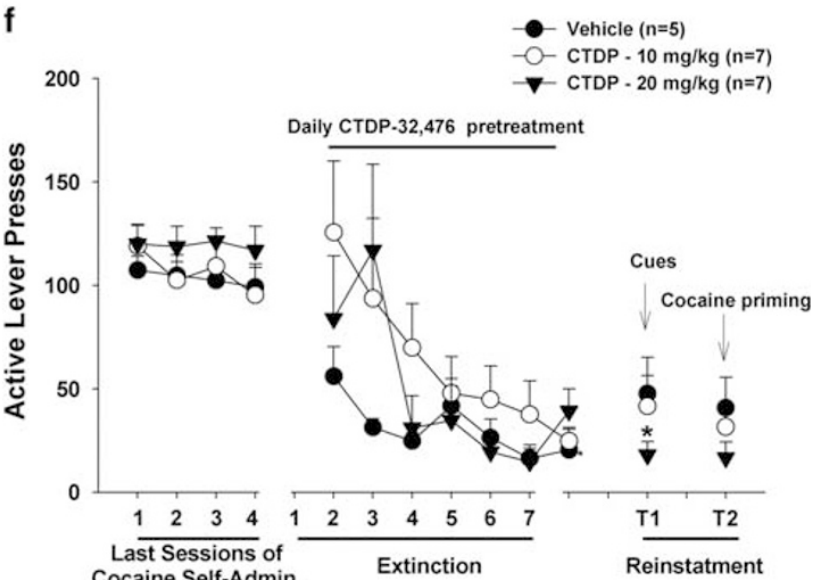

Figure 4 Effects of CTDP-32476 pretreatment on cocaine self-administration and reinstatement of drug-seeking behavior. CTDP-32476 (3, I0, and 20 mg/ kg, i.p. 30 min prior to testing) dose-dependently inhibited cocaine self-administration under FR2 reinforcement (a), lowered the break point for cocaine selfadministration under PR reinforcement (b), shifted the cocaine dose-response self-administration curve downward (c), and shifted the dose-dependent cocaine intake curve downward and to the right (d). A single injection of CTDP-32476 (I0, $20 \mathrm{mg} / \mathrm{kg}$, i.p., $2 \mathrm{~h}$ prior to cocaine priming) failed to block cocainetriggered reinstatement of drug-seeking behavior (e). Repeated daily administration of CTDP-32476 ( 10 and 20 mg/kg/day, i.p., 30 min prior to testing) during 7 days of extinction sessions significantly attenuated cocaine-associated cue-triggered reinstatement of drug-seeking behavior $(\mathrm{f})$. * $p<0.05, * * * 0.0 \mathrm{l}$, ***** $p<0.00$ I, compared with the baseline before CTDP-32476 administration ( $\mathrm{a}$ and b), compared with the vehicle control group at each dose (c and d) or compared with the last day of extinction (e).

cocaine self-administration dose-response curve downward. A two-way repeated-measures ANOVA over cocaine dose revealed a significant treatment (vehicle vs CTDP-32476) main effect $\left(F_{2,10}=19.67, p<0.001\right)$, a significant cocaine dose main effect $\left(F_{5,25}=16.80, p<0.001\right)$ and a significant treatment $\times$ cocaine dose interaction $\left(F_{10,50}=4.64, p<0.001\right)$. Figure $4 \mathrm{~d}$ shows total cocaine intake $(\mathrm{mg} / \mathrm{kg})$ at each cocaine dose in the different treatment groups, demonstrating that 
CTDP-32476 pretreatment dose-dependently shifted the cocaine dose-response curve downward and to the right $\left(F_{2,10}=19.09, p<0.001\right)$.

\section{Chronic CTDP-32476 Pretreatment Inhibits Relapse to Cocaine-Seeking Behavior}

We also assessed the effects of CTDP-32476 pretreatment on cocaine-induced relapse to drug-seeking behavior, using the reinstatement animal model of relapse. Figure $4 \mathrm{e}$ shows that a single injection of CTDP-32476, administered $2 \mathrm{~h}$ before cocaine priming, failed to alter cocaine-induced reinstatement of drug-seeking behavior (Figure 4e: $F_{2,23}=0.35$, $p=\mathrm{NS}$ ), whereas CTDP-32476 alone, at the dose range of $10-20 \mathrm{mg} / \mathrm{kg}$, produced mild reinstatement of drug-seeking behavior (data not shown). However, when CTDP-32476 was given repeatedly for 7 consecutive days during extinction, it significantly attenuated cue-induced reinstatement of drug-seeking behavior (Figure 4f: $F_{2,18}=4.11, p<0.05$, oneway ANOVA). Subsequent reinstatement responding triggered by cocaine priming was also reduced although this reduction was not statistically significant (Figure 4f: $F_{2,18}=1.44, p=\mathrm{NS}$ ). This may be related to the relatively lower reinstatement responses in the vehicle control group during the cocaine-induced reinstatement test.

\section{CTDP-32476 Pretreatment Attenuates Cocaine-Enhanced Extracellular NAc DA}

Finally, we observed the effects of CTDP-32476 pretreatment on cocaine-induced changes in NAc DA. Figure 5a shows extracellular NAc DA levels before and after CTDP-32476 and subsequent cocaine administration. Systemic administration of CTDP-32476 significantly elevated extracellular DA levels in a dose-dependent manner. Although CTDP-32476 pretreatment altered basal levels of extracellular DA before cocaine administration (Figure 5a), we used two methods to quantitatively evaluate the effects of CTDP-32476 pretreatment on cocaine-induced changes in extracellular DA. First, we compared the absolute amounts of DA (nmol/ sample) produced by cocaine in the presence and absence of CDTP-32476 pretreatment (Figure 5b), and found that CTDP-32476 pretreatment significantly blocked cocaineenhanced extracellular DA in a dose-dependent manner. Two-way ANOVA for repeated measures over time revealed a statistically significant CTDP-32476 treatment main effect $\left(\mathrm{F}_{2,19}=8.72, p<0.001\right)$, time main effect $\left(\mathrm{F}_{10,209}=4.90\right.$, $p<0.001)$, and treatment $\times$ time interaction $\left(F_{11,209}=7.98\right.$, $p<0.01)$. Second, we compared cocaine-induced percent change in DA over baseline in the presence or absence of CTDP-32476 pretreatment (Figure 5c). We found that CTDP-32476 pretreatment significantly attenuated cocaineinduced increases in extracellular NAc DA (Figure $5 \mathrm{c}$; $\left.F_{2,19}=16.74, p<0.001\right)$.

We also observed the interaction of CTDP-32476 and cocaine on extracellular DA by direct microinjections within the NAc. Figure 5d shows extracellular NAc DA levels before and after local perfusion of CTDP-32476 (30 $\mu \mathrm{M})$ and subsequent cocaine $(1,10$, and $100 \mu \mathrm{M})$ into the NAc, demonstrating that cocaine-enhanced extracellular DA was significantly blunted in the presence of local perfusion of $30 \mu \mathrm{M}$ CTDP-32476. Again, although CTDP-32476 pretreatment elevated basal levels of extracellular DA before cocaine administration, we compared cocaine-induced changes in extracellular DA content (nmols/sample, Figure $5 \mathrm{e}$ ) and cocaine-induced percent change over the new baseline immediately before cocaine infusion (Figure 5f). We found that, in the presence of CTDP-32476 $(30 \mu \mathrm{M})$, cocaine-enhanced extracellular NAc DA was blocked (Figure 5e, $F_{1,12}=16.28, p<0.001$; Figure 5f, $F_{1}$, ${ }_{12}=14.79, p<0.001$, two-way ANOVA). Histological examination indicated that the active microdialysis membranes spanned the length of the core and shell compartments of the NAc.

\section{DISCUSSION}

The present study was designed to characterize the pharmacological properties of CTDP-32476, and to evaluate, in animal models relevant to addiction, its potential utility as an agonist medication for the treatment of cocaine addiction. We found that CTDP-32476 is significantly different from many other DAT or MAT inhibitors: (1) CTDP-32476 is a highly potent and selective DAT inhibitor with an exceptional slow-onset long-lasting profile; (2) CTDP-32476 has much lower addictive potential than cocaine; (3) CTDP-32476 is a competitive $\left[{ }^{3} \mathrm{H}\right]$-cocaine-binding inhibitor at the DAT and functionally antagonizes cocaine's action on extracellular DA in the NAc; and (4) systemic administration of CTDP-32476 inhibits cocaine self-administration and cocaine cue-induced reinstatement of drug-seeking behavior. These findings suggest that CTDP-32476 is a novel and unique DAT inhibitor with both a slow-onset long-lasting profile and the ability to block the actions of subsequent cocaine. These profiles are similar to those shown in our previous work demonstrating that methadone is a longacting opioid receptor agonist that functionally antagonizes heroin's action on extracellular DA and heroin selfadministration (Peng et al, 2010). We therefore suggest that CTDP-32476 deserves further study as a potential agonist therapy for cocaine addiction.

With respect to methadone agonist therapies for addiction and dependence, there is little question that they can be clinically effective. After $>50$ years of clinical use, methadone agonist therapy clearly improves treatment retention and significantly decreases heroin use (Mattick et al, 2009). An overview of 5 meta-analyses and systematic reviews, summarizing results from 52 studies and 12,075 opioiddependent participants, found methadone to be more effective than detoxification, no treatment, or buprenorphine (Amato et al, 2005). With respect to nicotine agonist therapy, a meta-analysis of 150 trials, involving $>50,000$ smokers, revealed that nicotine agonist therapy increased the chances of stopping smoking by $50-70 \%$ (Stead et al, 2012). Similar findings of efficacy for nicotine agonist therapy in large-scale trials and meta-analyses are reported by many others (Silagy et al, 2004). Thus, agonist therapy has proven itself useful for both opioid and nicotine addiction, and there seems no a priori reason why agonist therapy-with the right properties (Peng et al, 2010)-should not be similarly effective for psychostimulant addiction.

It is well-documented that cocaine's rapid onset of action contributes to its highly-rewarding efficacy and addictive 


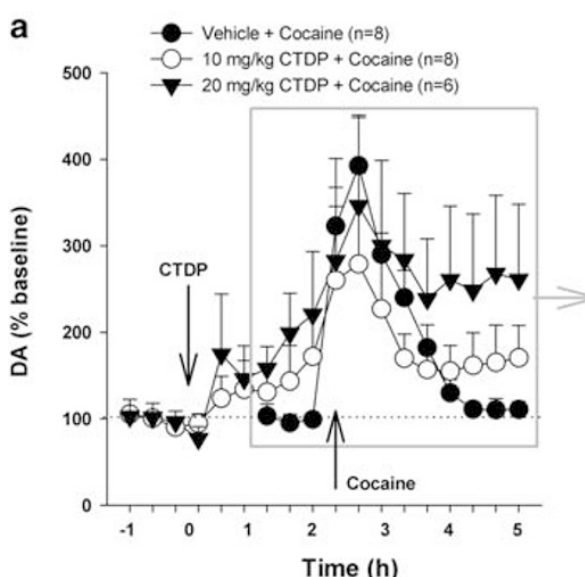

b

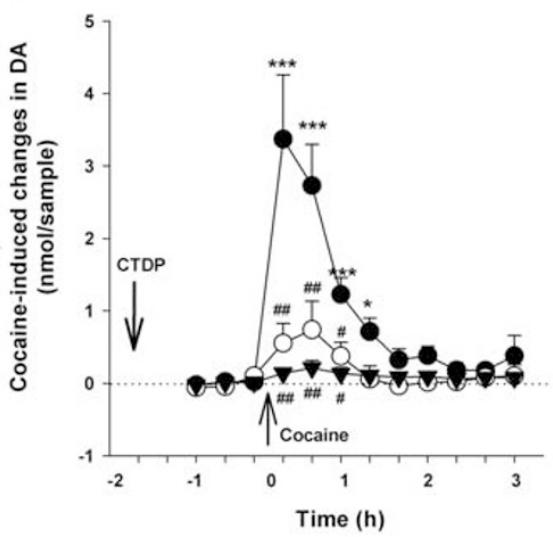

e

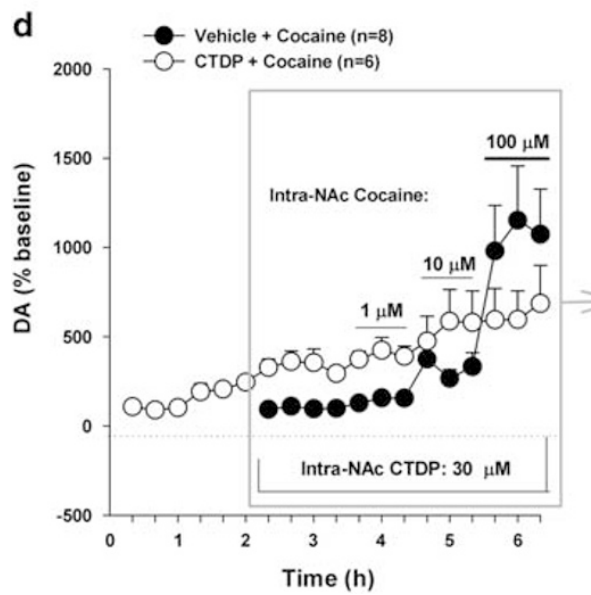

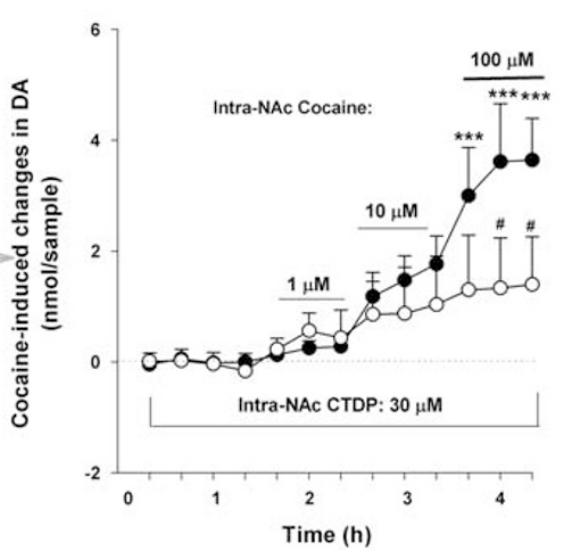

C

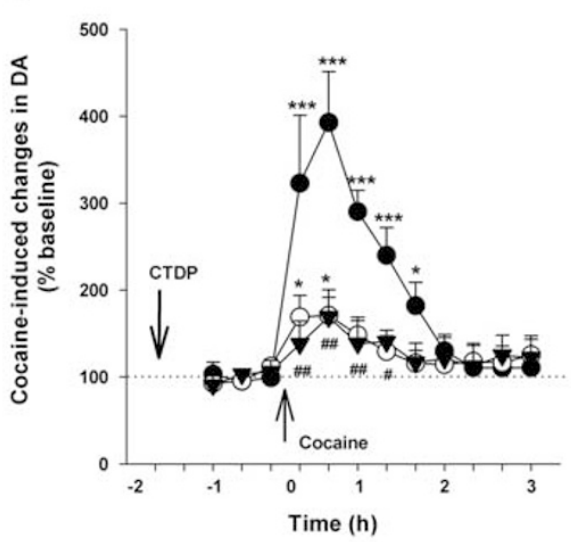

f

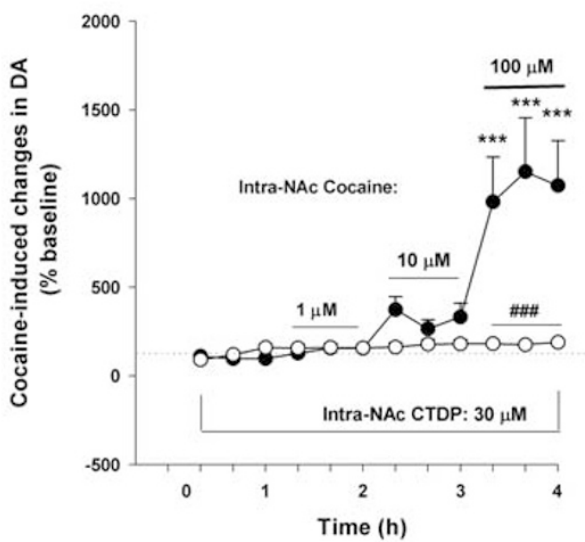

Figure 5 Effects of CTDP-32476 pretreatment on cocaine-enhanced extracellular NAc DA. (a) Extracellular NAc DA levels before and after CTDP-32476 and subsequent cocaine administration, illustrating that systemic administration of CTDP-32476 or cocaine significantly elevated extracellular DA. (b) Cocaineinduced changes in extracellular NAc DA (nmol/sample) in the presence or absence of CTDP-32476 pretreatment, by subtracting basal level (mean value of two samples before cocaine) of extracellular DA from DA level after cocaine administration. (c) Re-normalized data (percent change in DA over the new baseline immediately before cocaine), demonstrating a significant reduction in cocaine-enhanced NAc DA after CTDP-32476 pretreatment. (d) Cocaine- or CTDP-32476-induced changes in extracellular NAc DA after intra-NAc local administration. (e) Intra-NAc cocaine-induced changes in extracellular NAc DA (nmol/sample) in the presence or absence of intra-NAc CTDP-32476 co-administration, and ( $\mathrm{f}$ ) re-normalized NAc DA data (percent over new baseline immediately before cocaine administration), demonstrating that CTDP-32476 (30 $\mu \mathrm{M})$ pretreatment and co-administration blocked cocaine-enhanced NAc DA. ${ }^{*} p<0.05$, ** $p<0.0$ I, ***** $p<0.00$ I, compared with baseline in each group. ${ }^{\#} p<0.05,{ }^{\# \#} p<0.0$ I, \#\#\# $p<0.00$ I, compared with vehicle control group.

potential (Busto and Sellers, 1986; Kimmel et al, 2008; Kimmel et al, 2007), although not all studies support this view (Li et al, 2011). In rodents, different rates of cocaine delivery affect its addictive liability-drugs reaching the brain rapidly are more addictive than those that reach the brain slowly (Oldendorf, 1992; Samaha and Robinson, 2005; Wakabayashi et al, 2010). Similarly, in humans, the more rapidly cocaine (Volkow et al, 2000) or methylphenidate (Volkow et al, 2002) enters the brain, the greater the reported 'high'. On the basis of this, we previously proposed that slowonset long-acting MAT or DAT inhibitors should have lower addictive potential than cocaine (Froimowitz et al, 2000, 2007; Gardner et al, 2006; Peng et al, 2010). In the present study, multiple lines of evidence demonstrate that CTDP-32476 is an exceptional slow-onset (20-60 min) long-duration (6-12 h) DAT inhibitor that displays significantly lower addiction potential than cocaine. The mechanisms underlying such an exceptional slow-onset long-acting profile are incompletely understood. As stated above, CTDP-32476 is a metabolically stable DAT inhibitor with long half-life, that may persistently block the DAT and cause a long-lasting increase in extracellular NAc DA. Strikingly, intracranial local administration of CTDP-32476 produced as fast as increase in extracellular DA as cocaine, suggesting that delayed absorption and/or slower blood-brain transport/ diffusion may contribute to the slow-onset profile seen after systemic administration. A caveat to this study is that the effects produced by oral or intravenous administration of CTDP-32476 were not assessed. Thus, more studies are needed to further characterize the slow-onset long-acting profile and addictive potential of this novel compound under different routes of drug delivery.

Importantly, in the present study, we demonstrate that CTDP-32476 displayed significantly lower abuse potential than cocaine. This is based on the finding that drug-naive rats rapidly and reliably learned to self-administer cocaine, but not CTDP-32476. In rats that had acquired the selfadministration habit and achieved stable cocaine selfadministration, CTDP-32476 substitution maintained significantly lower rates of self-administration and intake. In 
addition, CTDP-32476 produced significantly lower PR break points than cocaine. Strikingly, this reduction in cocaine self-administration rate, cumulative drug intake or break point progressively enhances over time. This suggests that CTDP-32476 self-administration differs meaningfully from that of cocaine, and may therefore be predicted to have lower addictive potential than cocaine. This is consistent with our report that the slow-onset long-acting MAT inhibitor CTDP-31345 maintained significantly lower rates of self-administration in rats previously stable at cocaine selfadministration (Peng et al, 2010) and a previous report that the long-acting cocaine analog PTT failed to maintain selfadministration in non-human primates (Nader et al, 1997).

An important caveat attached to this assertion is the use of limited CTDP-32476 doses in the present study. It is possible that different doses might generate different outcomes. For example, CTDP-32476 may be self-administered at lower or higher doses. In addition, CTDP-32476 supported operant responding in rats initially trained to self-administer cocaine, although this behavior progressively declines over time. This may be related to its persistent (long-lasting) effects, not necessarily to a lower addictive potential. These issues should be addressed in future experiments in order to more thoroughly assess and characterize CTDP-32476's potential utility as an anti-addiction pharmacotherapy.

Another important finding of the present study is that coadministration of CTDP-32476 and cocaine inhibited $\left[{ }^{3} \mathrm{H}\right]$ cocaine binding to the DAT in in vitro cell cultures, and functionally antagonized cocaine's action on NAc DA as measured by in vivo brain microdialysis. Also, CTDP-32476 pretreatment dose-dependently inhibited cocaine-taking and cocaine-seeking behavior, as assessed by cocaine selfadministration under both FR2 and PR reinforcement and by a shift in the cocaine self-administration dose-response curve, suggesting that a reduction in cocaine's rewarding effects may underlie the reduction of cocaine selfadministration after CTDP-32476 administration. This action and the underlying mechanisms may be different from those produced by other DAT inhibitors such as GBR-12909, PTT, and some RTI compounds, although they also dose-dependently inhibit cocaine self-administration and attenuate cocaine intake (Glowa et al, 1996; Howell and Wilcox, 2001; Kimmel et al, 2008; Negus et al, 2009; Rothman et al, 2008; Tanda et al, 2009). The precise mechanisms underlying such actions remain unclear. Given that cocaine self-administration behavior is sensitive to fast changes in extracellular DA, the slow-onset long-lasting increase in DA produced by CTDP-32476 may underlie the reduction in cocaine self-administration observed in the present study. Another possibility is that CTDP-32476 may act as other atypical DAT inhibitors such as GBR-12909, benztropine, or modafinil-that induce a 'closed' or inwardfacing conformation upon binding to the DAT (Loland et al, 2008; Reith et al, 2015). Because cocaine has higher binding affinity for the more 'open' conformation, a compound inducing a 'closed' conformation would be more likely to attenuate cocaine binding to the DAT and thus be less effective as a DAT inhibitor. However, this possibility appears low as intra-NAc local perfusion of CTDP-32476 produced a fast-onset increase in extracellular DA, similar to cocaine.
We note that a single injection of CTDP-32476, when given $2 \mathrm{~h}$ before cocaine priming, failed to alter cocaineinduced reinstatement of drug-seeking behavior, whereas chronic administration of CTDP-32476 for 7 consecutive days did. The mechanisms underlying these different findings are unclear, but some possibilities would appear to present themselves. First, cocaine priming produces an increase in both NAc DA and glutamate, and glutamate has been proposed to have an important role in reinstatement of drug-seeking behavior (Kalivas and Volkow, 2005). Possible lack of effect on cocaine-enhanced glutamate may (in part) explain the lack of effect of acute CTDP-32476 on cocaine-induced reinstatement. Second, cocaine-dependent subjects have been shown to have significant deficits in brain DA function (Koob et al, 2004; Kuhar and Pilotte, 1996). Thus, it might well be expected that repeated, but not single dose, CTDP-32476 administration may be more effective in renormalization (elevation) of extracellular DA, thereby decreasing motivation for drug-seeking behavior (ie, drug craving).

On the basis of above findings that: (1) CTDP-32476 is a highly potent and selective DAT inhibitor and also a cocainebinding inhibitor at the DAT; (2) CTDP-32476 exhibits significantly lower addictive potential than cocaine; and (3) CTDP-32476 pretreatment inhibits cocaine-taking and cocaine-seeking behavior likely by antagonizing cocaineenhanced extracellular DA, we suggest that CTDP-32476 deserves further research as a potential agonist pharmacotherapy for the treatment of cocaine addiction. A possible limitation to the use of CTDP-32476 as a medication is its possible addictive potential. However, this seems low. Furthermore, CTDP-32476's relatively mild and limited reinforcing properties may be helpful in relieving dysphoria, craving, or abstinence symptoms-thereby improving patient compliance and medication effectiveness.

\section{FUNDING AND DISCLOSURE}

This research was supported by the Intramural Research Program of the National Institute on Drug Abuse, National Institutes of Health, USA, the National Basic Research Program of China (research grant number 2015CB553504), the National Natural Science Foundation of China (\#81573405), and the Beijing Nova Program (xx2014A014). The authors declare no conflict of interest.

\section{REFERENCES}

Allouche S, Noble F, Marie N (2014). Opioid receptor desensitization: mechanisms and its link to tolerance. Front Pharmacol 5: 280 .

Amato L, Davoli M, Perucci C, Ferri M, Faggiano F, Mattick RP (2005). An overview of systematic reviews of the effectiveness of opioid maintenance therapies: available evidence to inform clinical practice and research. J Subst Abuse Treat 28: 321-329.

Baumann MH, Char GU, De Costa BR, Rice KC, Rothman RB (1994). GBR12909 attenuates cocaine-induced activation of mesolimbic dopamine neurons in the rat. J Pharmacol Exp Ther 271: 1216-1222.

Budygin EA, Kilpatrick MR, Gainetdinov RR, Wightman RM (2000). Correlation between behavior and extracellular dopamine 
levels in rat striatum: comparison of microdialysis and fast-scan cyclic voltammetry. Neurosci Lett 281: 9-12.

Busto U, Sellers EM (1986). Pharmacokinetic determinants of drug abuse and dependence. A conceptual perspective. Clin Pharmacokinet 11: 144-153.

Carroll FI, Howard JL, Howell LL, Fox BS, Kuhar MJ (2006). Development of the dopamine transporter selective RTI-336 as a pharmacotherapy for cocaine abuse. Aaps J 8: E196-E203.

Cheng YC, Prusoff WH (1973). Relationship between the inhibition constant (KI) and the concentration of inhibitor which causes 50 per cent inhibition (I50) of an enzymatic reaction. Biochem Pharmacol 22: 3099-3108.

Espana RA, Roberts DC, Jones SR (2008). Short-acting cocaine and long-acting GBR-12909 both elicit rapid dopamine uptake inhibition following intravenous delivery. Neuroscience 155: 250-257.

Everitt BJ, Belin D, Economidou D, Pelloux Y, Dalley JW, Robbins TW (2008). Review. Neural mechanisms underlying the vulnerability to develop compulsive drug-seeking habits and addiction. Philos Trans $R$ Soc Lond B Biol Sci 363: 3125-3135.

Froimowitz M, Gu Y, Dakin LA, Nagafuji PM, Kelley CJ, Parrish D et al (2007). Slow-onset, long-duration, alkyl analogues of methylphenidate with enhanced selectivity for the dopamine transporter. J Med Chem 50: 219-232.

Froimowitz M, Wu K-M, Moussa A, Haidar RM, Jurayj J, George C et al (2000). Slow-onset, long-duration 3-(3',4'-dichlorophenyl)-1indanamine monoamine reuptake blockers as potential medications to treat cocaine abuse. J Med Chem 43: 4981-4992.

Gardner EL, Liu X, Paredes W, Giordano A, Spector J, Lepore M et al (2006). A slow-onset, long-duration indanamine monoamine reuptake inhibitor as a potential maintenance pharmacotherapy for psychostimulant abuse: effects in laboratory rat models relating to addiction. Neuropharmacology 51: 993-1003.

Gerra G, Maremmani I, Capovani B, Somaini L, Berterame S, Tomas-Rossello J et al (2009). Long-acting opioid-agonists in the treatment of heroin addiction: why should we call them "substitution"? Subst Use Misuse 44: 663-671.

Glowa JR, Fantegrossi WE, Lewis DB, Matecka D, Rice KC, Rothman RB (1996). Sustained decrease in cocaine-maintained responding in rhesus monkeys with 1-[2-[bis(4-fluorophenyl) methoxy] ethyl]-4-(3-hydroxy-3-phenylpropyl) piperazinyl decanoate, a long-acting ester derivative of GBR 12909. J Med Chem 39: 4689-4691.

Gorelick DA, Gardner EL, Xi ZX (2004). Agents in development for the management of cocaine abuse. Drugs 64: 1547-1573.

Grabowski J, Shearer J, Merrill J, Negus SS (2004). Agonist-like, replacement pharmacotherapy for stimulant abuse and dependence. Addict Behav 29: 1439-1464.

Howell LL, Wilcox KM (2001). The dopamine transporter and cocaine medication development: drug self-administration in nonhuman primates. J Pharmacol Exp Ther 298: 1-6.

Jin Z-L, Gao N, Zhou D, Chi M-G, Yang X-M, Xu J-P (2012). The extracts of Fructus Akebiae, a preparation containing $90 \%$ of the active ingredient hederagenin: serotonin, norepinephrine and dopamine reuptake inhibitor. Pharmacol Biochem Behav 100: 431-439.

Kalivas PW, Volkow ND (2005). The neural basis of addiction: a pathology of motivation and choice. Am J Psychiatry 162: 1403-1413.

Kimmel HL, Negus SS, Wilcox KM, Ewing SB, Stehouwer J, Goodman MM et al (2008). Relationship between rate of drug uptake in brain and behavioral pharmacology of monoamine transporter inhibitors in rhesus monkeys. Pharmacol Biochem Behav 90: 453-462.

Kimmel HL, O'Connor JA, Carroll FI, Howell LL (2007). Faster onset and dopamine transporter selectivity predict stimulant and reinforcing effects of cocaine analogs in squirrel monkeys. Pharmacol Biochem Behav 86: 45-54.
Koob GF, Ahmed SH, Boutrel B, Chen SA, Kenny PJ, Markou A et al (2004). Neurobiological mechanisms in the transition from drug use to drug dependence. Neurosci Biobehav Rev 27: 739-749.

Kuhar MJ, Pilotte NS (1996). Neurochemical changes in cocaine withdrawal. Trends Pharmacol Sci 17: 260-264.

Li SM, Kopajtic TA, O'Callaghan MJ, Agoston GE, Cao J, Newman AH et al (2011). N-substituted benztropine analogs: selective dopamine transporter ligands with a fast onset of action and minimal cocaine-like behavioral effects. J Pharmacol Exp Ther 336: 575-585.

Li X, Li J, Gardner EL, Xi ZX (2010). Activation of mGluR7s inhibits cocaine-induced reinstatement of drug-seeking behavior by a nucleus accumbens glutamate-mGluR2/3 mechanism in rats. $J$ Neurochem 114: 1368-1380.

Loland CJ, Desai RI, Zou MF, Cao J, Grundt P, Gerstbrein K et al (2008). Relationship between conformational changes in the dopamine transporter and cocaine-like subjective effects of uptake inhibitors. Mol Pharmacol 73: 813-823.

Mattick RP, Breen C, Kimber J, Davoli M (2009). Methadone maintenance therapy versus no opioid replacement therapy for opioid dependence. Cochrane Database Syst Rev 2009 (3): CD002209.

Nader MA, Grant KA, Davies HM, Mach RH, Childers SR (1997). The reinforcing and discriminative stimulus effects of the novel cocaine analog 2beta-propanoyl-3beta-(4-tolyl)-tropane in rhesus monkeys. J Pharmacol Exp Ther 280: 541-550.

Nakachi N, Kiuchi Y, Inagaki M, Inazu M, Yamazaki Y, Oguchi K (1995). Effects of various dopamine uptake inhibitors on striatal extracellular dopamine levels and behaviours in rats. Eur $J$ Pharmacol 281: 195-203.

Negus SS, Mello NK, Kimmel HL, Howell LL, Carroll FI (2009). Effects of the monoamine uptake inhibitors RTI-112 and RTI-113 on cocaine- and food-maintained responding in rhesus monkeys. Pharmacol Biochem Behav 91: 333-338.

Newman AH, Kulkarni S (2002). Probes for the dopamine transporter: new leads toward a cocaine-abuse therapeutic-a focus on analogues of benztropine and rimcazole. Med Res Rev 22: 429-464.

Oldendorf WH (1992). Some relationships between addiction and drug delivery to the brain. NIDA Res Monogr 120: 13-25.

Peng X-Q, Xi Z-X, Li X, Spiller K, Li J, Chun L et al (2010). Is slowonset long-acting monoamine transport blockade to cocaine as methadone is to heroin? implication for anti-addiction medications. Neuropsychopharmacology 35: 2564-2578.

Platt DM, Rowlett JK, Spealman RD (2002). Behavioral effects of cocaine and dopaminergic strategies for preclinical medication development. Psychopharmacology 163: 265-282.

Reavill C, Boyfield I, Coldwell M, Nelson P (2000). Comparative pharmacological study of ropinirole (SKF-101468) and its metabolites in rats. J Pharmacy Pharmacol 52: 1129-1135.

Reith ME, Blough BE, Hong WC, Jones KT, Schmitt KC, Baumann $\mathrm{MH}$ et al (2015). Behavioral, biological, and chemical perspectives on atypical agents targeting the dopamine transporter. Drug Alcohol Depend 147: 1-19.

Reith ME, Xu C, Carroll FI, Chen NH (1998). Inhibition of [3H] dopamine translocation and $[3 \mathrm{H}]$ cocaine analog binding: a potential screening device for cocaine antagonists. Methods Enzymol 296: 248-259.

Richardson NR, Roberts DCS (1996). Progressive ratio schedules in drug self-administration studies in rats: a method to evaluate reinforcing efficacy. J Neurosci Methods 66: 1-11.

Rothman RB, Baumann MH, Prisinzano TE, Newman AH (2008). Dopamine transport inhibitors based on GBR12909 and benztropine as potential medications to treat cocaine addiction. Biochem Pharmacol 75: 2-16.

Runyon SP, Carroll FI (2006). Dopamine transporter ligands: recent developments and therapeutic potential. Curr Top Med Chem 6: 1825-1843. 
Samaha AN, Robinson TE (2005). Why does the rapid delivery of drugs to the brain promote addiction? Trends Pharmacol Sci 26: 82-87.

Silagy C, Lancaster T, Stead L, Mant D, Fowler G (2004). Nicotine replacement therapy for smoking cessation. Cochrane Database Syst Rev 2004 (3): CD000146.

Stead LF, Perera R, Bullen C, Mant D, Hartmann-Boyce J, Cahill K et al (2012). Nicotine replacement therapy for smoking cessation. Cochrane Database Syst Rev 2012 (11): CD000146.

Tanda G, Newman AH, Ebbs AL, Tronci V, Green JL, Tallarida RJ et al (2009). Combinations of cocaine with other dopamine uptake inhibitors: assessment of additivity. J Pharmacol Exp Ther 330: 802-809.

Vocci F, Ling W (2005). Medications development: successes and challenges. Pharmacol Ther 108: 94-108.

Volkow ND, Fowler JS, Wang GJ, Ding YS, Gatley SJ (2002). Role of dopamine in the therapeutic and reinforcing effects of methylphenidate in humans: results from imaging studies. Eur Neuropsychopharmacol 12: 557-566.
Volkow ND, Wang GJ, Fischman MW, Foltin R, Fowler JS, Franceschi D et al (2000). Effects of route of administration on cocaine induced dopamine transporter blockade in the human brain. Life Sci 67: 1507-1515.

Wakabayashi KT, Weiss MJ, Pickup KN, Robinson TE (2010). Rats markedly escalate their intake and show a persistent susceptibility to reinstatement only when cocaine is injected rapidly. J Neurosci 30: 11346-11355.

Wise RA (1996). Neurobiology of addiction. Curr Opin Neurobiol 6: 243-251.

Xi ZX, Gardner EL (2008). Hypothesis-driven medication discovery for the treatment of psychostimulant addiction. Curr Drug Abuse Rev 1: 303-327.

Xi ZX, Spiller K, Pak AC, Gilbert J, Dillon C, Li X et al (2008). Cannabinoid CB1 receptor antagonists attenuate cocaine's rewarding effects: experiments with self-administration and brain-stimulation reward in rats. Neuropsychopharmacology 33: 1735-1745. 